\title{
eHealth cognitive rehabilitation for brain tumor patients: results of a randomized controlled trial
}

\author{
Sophie D. van der Linden ${ }^{1,2} \cdot$ Geert-Jan M. Rutten ${ }^{1}$ Linda Dirven ${ }^{3,4} \cdot$ Martin J. B. Taphoorn $^{3,4} \cdot$ Djaina D. Satoer $^{5}$. \\ Clemens M. F. Dirven ${ }^{5} \cdot$ Margriet M. Sitskoorn ${ }^{2} \cdot$ Karin Gehring ${ }^{1,2} \mathbb{C}$
}

Received: 22 June 2021 / Accepted: 12 August 2021 / Published online: 6 September 2021

(c) The Author(s) 2021

\begin{abstract}
Background Evidence-based cognitive rehabilitation programs for brain tumor patients are not widely available, despite the high need. We aimed to evaluate the effects of a tablet-based cognitive rehabilitation program on cognitive performance, cognitive complaints, fatigue, and psychological distress in primary brain tumor patients following neurosurgery. Also, attrition, adherence and patient satisfaction with the program were evaluated.

Methods Adults with presumed low-grade glioma and meningioma were recruited before surgery. Three months thereafter, participants were allocated to the intervention group or waiting-list control group using minimization. The 10-week eHealth app ReMind, based on the effective face-to-face intervention, consisted of psychoeducation, strategy-training and attention retraining. Performance-based cognitive outcomes and patient-reported outcomes were assessed before surgery and 3, 6 and 12 months thereafter. Mean scores, percentages of cognitively impaired individuals and reliable change indices (RCIs) were compared between groups.

Results Sixty-two out of 183 eligible patients were randomized. Of the people who declined, $56 \%$ reported that participation would to be too burdensome. All participants found a tablet-app suitable for delivery of cognitive rehabilitation and $90 \%$ rated the program as "good" or "excellent". Performance-based cognitive outcomes and patient-reported outcomes did not significantly differ in group means over time nor RCIs between the intervention (final $n=20$ ) and control group (final $n=25$ ). Conclusions Recruitment at this early stage was difficult, resulting in limited statistical power. No significant effects were demonstrated, while adherence and satisfaction with the eHealth program were good. In clinical practice, ReMind may be helpful, if timing would be adapted to patients' needs.
\end{abstract}

Keywords Cognitive rehabilitation $\cdot$ eHealth $\cdot$ Glioma $\cdot$ Meningioma $\cdot$ Neurosurgery $\cdot$ Randomized controlled trial

Karin Gehring

k.gehring@uvt.nl

1 Department of Neurosurgery, Elisabeth-TweeSteden Hospital, Tilburg, the Netherlands

2 Department of Cognitive Neuropsychology, Tilburg University, Room S219, P.O. Box 90153, 5000 LE Tilburg, the Netherlands

3 Department of Neurology, Leiden University Medical Center, Leiden, the Netherlands

4 Department of Neurology, Haaglanden Medical Center, The Hague, the Netherlands

5 Department of Neurosurgery, Erasmus Medical Center, Rotterdam, the Netherlands

\section{Introduction}

Cognitive deficits are common in adults with primary brain tumors [1-6]. Despite the fact that these cognitive deficits are often mild and diffuse in nature, they can lead to problems in social and professional functioning, which affect families and society [7-9]. In addition, brain tumor patients often face severe fatigue, distress and/or language problems [10-14], which may all contribute to lower quality of life. Patients with meningioma and patients with glioma with favorable prognosis $[15,16]$ in particular, live longer with a variety of symptoms, including cognitive deficits. Therefore, treatment of cognitive deficits has become increasingly important in the management of the disease [17].

The few studies that have been conducted on cognitive rehabilitation in adults with brain tumors demonstrated 
positive effects on cognitive outcomes in patients in different stages of the disease [18-23]. In a previous randomized controlled trial (RCT) of our group, patients with glioma who underwent cognitive rehabilitation performed significantly better on tests of memory and attention, and reported less cognitive complaints and mental fatigue afterwards [19, 20]. To increase the accessibility of this cognitive rehabilitation program [24] in a cost-efficient and patient-friendly way, we developed a tablet-based version of the program. An initial pilot study demonstrated that post-surgical cognitive rehabilitation via this eHealth intervention was feasible in adults with low-grade glioma and meningioma [25].

In this RCT, we investigated the effects of the tabletbased program in adults with low-grade glioma and meningioma, cognitive performance as primary outcome and selfreported cognitive functioning, fatigue, and psychological distress [26] as secondary outcomes. Enrollment, attrition, adherence, and patient satisfaction were evaluated as well.

\section{Methods}

The study was conducted in accordance with the Declaration of Helsinki [27] and was approved by the local medical ethical review board (METC Brabant: NL51152.028.14). All participants provided written informed consent. Greater methodological details were described in a previously published study protocol [26] and feasibility study [25].

\section{Participants}

Adult patients with presumed low-grade glioma or meningioma scheduled for resective surgery were screened for eligibility at the Elisabeth-TweeSteden Hospital Tilburg, Haaglanden Medical Center The Hague, and Erasmus Medical Center Rotterdam. People were not eligible if: they had multifocal disease or multiple brain tumors; had undergone brain tumor resection in the last year; received chemotherapy or radiotherapy in the last two years; had a history of progressive neurological disease/severe psychiatric disorder or substance abuse; had been diagnosed with an acute neurological/psychiatric disorder in the last two years; lacked a basic proficiency in Dutch; had an IQ below 85; had a KPS below 70; or had visual, language or motor impairment limiting the ability to complete neuropsychological assessment. Participants were also excluded after surgery if they suffered from surgery-related complications or if they were referred to conventional cognitive rehabilitation.

With the use of $\mathrm{G}^{*}$ Power, an a priori power analysis for F-tests was conducted, to determine the minimum required sample size. The analysis indicated that, with alpha set at 0.05 , power at 0.80 and an effect size of 0.37 (based on effect sizes of our previous RCT), group sizes of 50 were required
(100 participants in total). With an expected attrition rate of $33 \%$, we aimed to include 150 participants before surgery and to evaluate data from 100 participants.

\section{Design, randomization and procedure}

Patients in this multicenter prospective RCT were invited to participate prior to surgery. After patients' approval, but before randomization, informal caregivers were also invited to participate and to support patients with the intervention. Participants underwent neuropsychological assessments before surgery (T0) and three months after surgery (T3). At T3, participants were assigned to the intervention group or to the waiting-list control group in a 1:1 ratio. The minimization method [28] was used to balance groups for age, tumor histology, baseline cognitive test performance, physical health status (ASA score) and participation in other psychosocial interventions [26]. Access to an online minimization program was provided by the Netherlands Cancer Institute Amsterdam [29]. With the use of this software, the allocation sequence remained concealed from the researcher. However, the researcher was not blinded and assigned participants to the intervention. Research assistants who carried out the neuropsychological assessments were blinded. Neuropsychological follow-up assessments were conducted immediately after the intervention (6 months post-surgery; T6) and one year post-surgery (T12). Participants in the waiting-list control group were offered the opportunity to follow the cognitive rehabilitation program, with guidance from the researcher, after the last study assessment.

\section{Intervention}

The tablet-based cognitive rehabilitation program ReMind includes psychoeducation, strategy training and an attention retraining game. The psychoeducational information and strategy training are spread over six modules, namely (1) Cognitive functions, (2) Influences, (3) Compensation, (4) Attention, (5) Planning \& Control, and (6) Memory. In each module, information about cognitive functions is given. Subsequently, compensatory strategies are provided, together with fill-in exercises to practice with the strategies in daily life. For example, patients learn to minimize distraction and to optimally use external devices for support. The modules include several user-friendly technical features, for example the possibility of using videos/audio clips in addition to written information, to look up frequently-used terms, and to send e-mails to the caregiver or professional if the patient gets stuck. The retraining includes game-like hierarchically graded exercises aimed at training different forms of attention (i.e., Sustained, Selective, Alternating and Divided attention). It includes visual and auditory exercises, wherein both verbal and numeric stimuli are presented. The 
ReMind-app works on iOS systems of iPad devices (Apple Inc) and is not yet publicly available.

The advice (presented in a leaflet) to patients was to spend three hours a week (spread over the week) on the program to complete the program in ten weeks. Telephone assistance was provided by the researcher every 2 weeks. During this telephone contact, participants could share their questions, difficulties, and experiences, and they were also encouraged to continue working on the program.

\section{Outcome measures}

The primary outcome of this RCT was change in performance-based outcomes. Secondary outcomes were changes in patient-reported outcomes (PROs) and tertiary outcomes were enrolment and attrition, adherence and patient satisfaction.

\section{Enrollment and attrition}

The number of patients invited to participate was recorded, as were the numbers of patients who agreed or declined, and the reasons for decline and dropout.

\section{Adherence and patient satisfaction}

The number of completed modules in the strategy training and the number of completed exercises in the retraining, each expressed in percentages, were used to measure adherence to the program. If a strategy training module was not fully completed, module sections were counted. Adherence was considered sufficient if patients completed $\geq 80 \%$ of both the strategy training and the retraining. Experiences with the program were evaluated with a study-specific evaluation questionnaire [25].

\section{Performance-based cognitive outcomes}

Cognitive functioning was measured with the computerized neuropsychological test battery Central Nervous System Vital Signs (CNS VS, LCC, Morrisville, North Carolina) [30]. CNS VS assesses the following domains: verbal memory, visual memory, processing speed, psychomotor speed, reaction time, complex attention and cognitive flexibility. Additionally, working memory was assessed with the Digit Span Test of the Wechsler Adult Intelligence Scale (WAISIII), and verbal fluency was measured with a Letter Fluency test [31]. Patient scores were converted to $Z$-scores (correcting for age, sex and/or education) using Dutch norms [31-33]. Impaired cognitive functioning was defined as $Z$-scores $\leq-1.5$.

\section{Patient-reported outcomes (PROs)}

The Cognitive Failures Questionnaire (CFQ) was used to measure self-reported cognitive failures. Additionally, two index scores of the Behaviour Rating Inventory of Executive Function (BRIEF-A) were evaluated, namely Behavioral regulation and Metacognition. Two subscales of the Multidimensional Fatigue Inventory (MFI-20) were also analyzed to evaluate the level of physical fatigue and mental fatigue. Symptoms of anxiety and depression were examined using the Hospital Anxiety and Depression Scale (HADS). Scores were converted to $Z$-scores based on published norms [34-37] and, $Z$-scores $\leq-1.5$ were considered as low.

\section{Statistical analysis}

Statistical analyses were conducted using SPSS version 24 (IBM Inc, Armonk, New York), with alpha set at 0.05 .

Regarding enrollment and attrition, analysis of nonresponse bias was conducted, to explore possible differences between people who declined participation and people who provided informed consent at T0. Subsequently, pre-intervention (T3) sociodemographic, clinical and neuropsychological characteristics were compared between the intervention and control group using independent sample $t$-tests, Chi-square tests or Fisher's exact tests.

To study the performance-based cognitive outcomes and patient-reported outcomes, we used repeated measures ANOVAs to assess effects of time and group on the outcome variables. In addition, chi-square tests were conducted to evaluate frequencies of participants with impairment (Z-scores $\leq-1.5$ ) at each time-point. (i.e., T3, T6, T12).

Reliable change indices (RCIs) were calculated for the cognitive test scores and PROs, by comparing change in individual scores to observed changes in the study's control group, while taking into account practice effects, natural recovery and measurement errors [38]. Reliable improvement was defined as RCI values above +1.645 and decline below -1.645 (based on an alpha of 0.10 , corresponding to a $90 \%$ confidence interval). RCIs were calculated over the first time-interval (T3-T6) and over the second interval (T3-T12). Numbers of participants who reliably improved/ declined on one or more outcomes were compared between groups for test scores and PROs using Chi-square tests.

\section{Results}

\section{Enrollment and attrition}

Figure 1 presents the flow of participants throughout the trial. Prior to surgery, 183 out of 330 patients were eligible based on the inclusion/exclusion criteria and were invited 


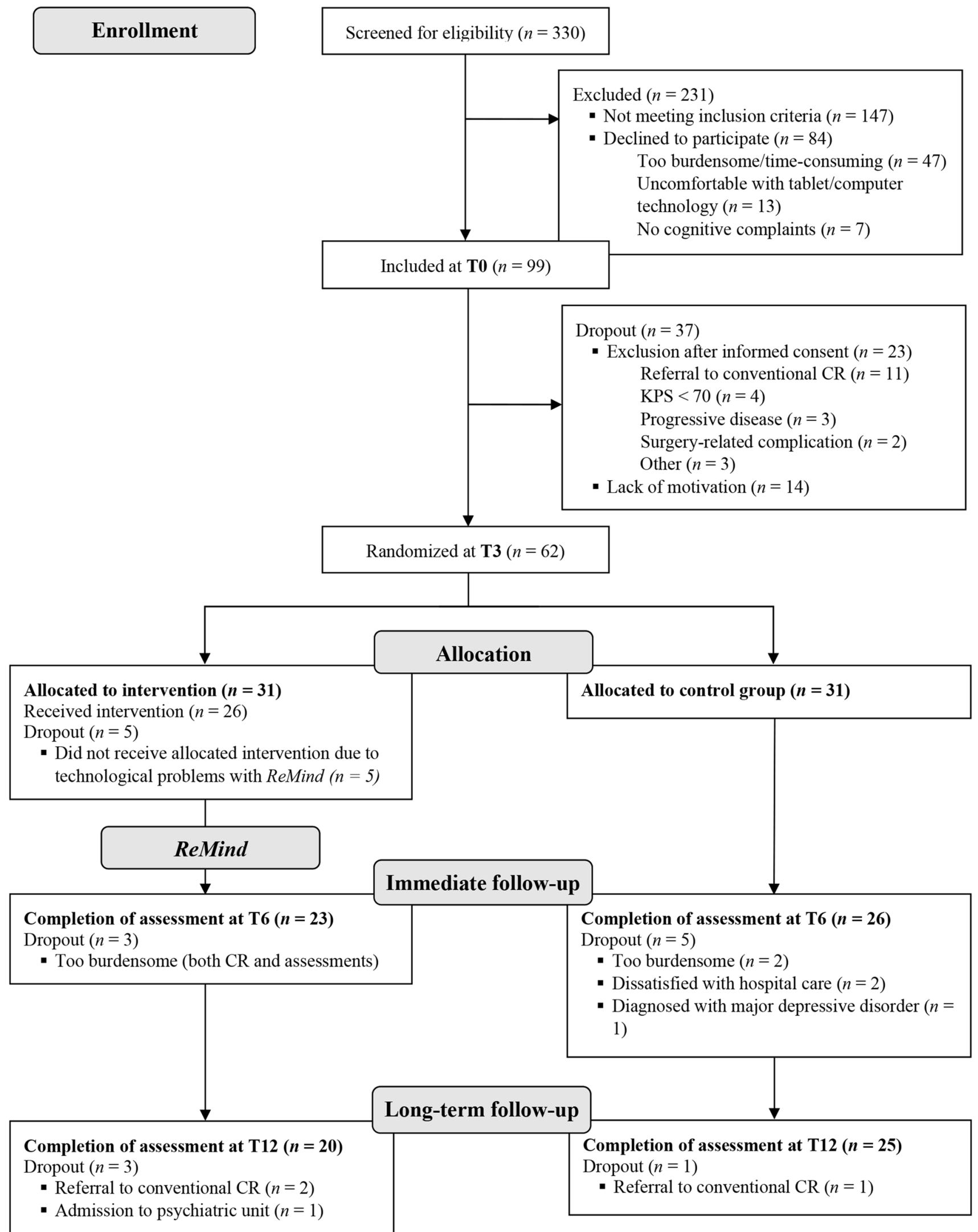

Fig. 1 Flow of participants through the trial. CR cognitive rehabilitation; KPSkarnofsky performance status. Neuropsychological assessments took place one day before surgery (T0), and 3 (T3), 6 (T6) and 12 (T12) months thereafter 
to participate, of whom 99 provided informed consent and 84 declined participation. The most important reason for decline was that patients anticipated that it would be too burdensome and/or too time-consuming ( $n=47 ; 56 \%)$. Non-response analysis with available data of 75/84 decliners showed that study participants were significantly younger $\left(\mathrm{M}_{\mathrm{diff}}=-8.09, p=.03\right)$, were more often highly educated (50\% vs. $20 \%, p<.05)$ and were more often diagnosed with a LGG $(32 \%$ vs. $11 \%, p<.05)$ compared to non-responders. No significant differences were observed in sex, tumor lateralization or proportions of patients with cognitive impairment.

From T0 to T3, before randomization, 37 participants dropped out of the study. Most important reasons were lack of motivation $(n=14$; including 8 patients who wanted to devote full attention to work resumption) and referral to conventional cognitive rehabilitation $(n=11)$. Three months after surgery, 62 participants were randomized to the intervention or control group. In total, 17 participants dropped out of the study between T3 and T12 for various reasons (see Fig. 1). As a result, data of 49 participants were included at $\mathrm{T} 6$ and of 45 participants at T12.

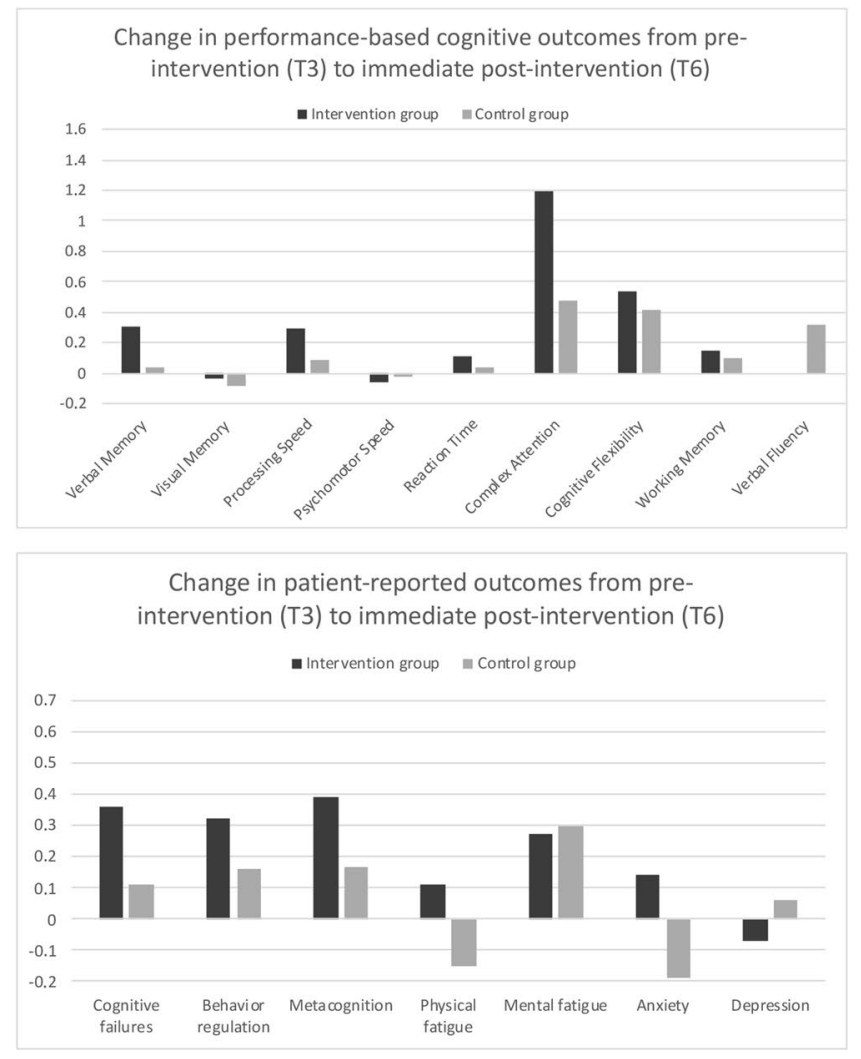

Fig. 2 Mean changes in Z-scores for performance-based cognitive outcomes and patient-reported outcomes from pre-intervention to immediate follow-up and from pre-intervention to longer-term follow-

\section{Patient characteristics}

Participants in the intervention group were significantly younger $\left(\mathrm{M}_{\mathrm{diff}}=-6.92, p=.03\right)$ and the proportion of women was significantly higher $(74 \%$ vs. $46 \%, p<.05)$ compared to the control group. No significant differences between groups were observed regarding years of education or educational level. Fourteen participants had adjuvant treatment with radiotherapy. Ten patients received chemotherapy within one-year post-surgery (i.e., temozolomide (TMZ), and one patient received adjuvant procarbazine, lomustine and vincristine (PCV) as well). Sixteen participants in the intervention group (70\%) and 20 participants in the control group (77\%) chose to involve an informal caregiver. Mean preintervention scores of cognitive performance and PROs did not differ significantly between groups (Table 1 ).

\section{Adherence and patient satisfaction}

Participants completed on average $85 \%$ of the strategy training and $91 \%$ of the retraining. Sufficient adherence (completion of $\geq 80 \%$ of both the strategy training and retraining)

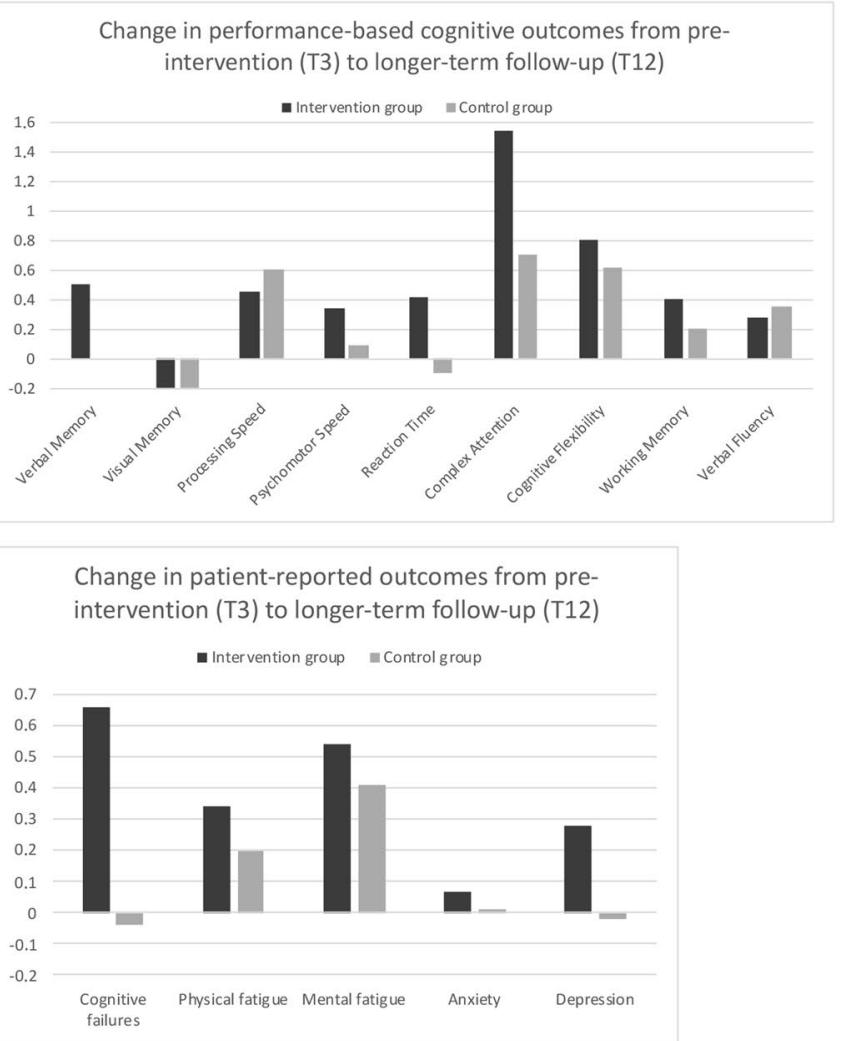

up for the intervention group versus control group. Positive change scores indicate improvement on the outcome variables, whereas negative scores indicate decline 
Table 1 Sociodemographic and clinical characteristics of intervention group and control group

\begin{tabular}{|c|c|c|c|}
\hline Characteristic & $\begin{array}{l}\text { Intervention group } \\
(n=23)\end{array}$ & $\begin{array}{l}\text { Control } \\
\text { group }(n=26)\end{array}$ & $p$ value \\
\hline Age at T3 (Mean; SD) & $45.7(11.7)$ & $52.6(10.4)$ & $0.033^{*}$ \\
\hline Sex $(n$ female; $\%)$ & $17(74)$ & $12(46)$ & $0.048 *$ \\
\hline Years of education (Mean; SD) & $15.4(3.6)$ & $15.1(3.6)$ & 0.766 \\
\hline Level of education $(n ; \%)$ & & & 0.334 \\
\hline Low & $4(17)$ & $5(19)$ & \\
\hline Middle & $4(17)$ & $9(35)$ & \\
\hline High & $15(65)$ & $12(46)$ & \\
\hline Physical status $(n ; \%)^{\mathrm{a}}$ & & & 1.00 \\
\hline ASA I/II & $23(100)$ & $25(96)$ & \\
\hline ASA III/IV & - & $1(4)$ & \\
\hline Tumor histology $(n ; \%)^{\mathrm{b}}$ & & & 0.821 \\
\hline Grade 1 meningioma & $13(57)$ & $14(54)$ & \\
\hline Grade 2 meningioma & $1(4)$ & $1(4)$ & \\
\hline Grade 2 glioma & $9(39)$ & $10(39)$ & \\
\hline Grade 3 glioma & - & $1(4)$ & \\
\hline Tumor hemisphere $^{\mathrm{c}}(n ; \%)$ & & & 0.681 \\
\hline Left & $11(48)$ & $11(42)$ & \\
\hline Right & $11(48)$ & $14(54)$ & \\
\hline Bilateral & $1(4)$ & $1(4)$ & \\
\hline Tumor localization $^{\mathrm{d}}$ & & & 0.240 \\
\hline Frontal & $13(57)$ & $11(42)$ & \\
\hline Parietal & $3(13)$ & $2(8)$ & \\
\hline Temporal & $5(22)$ & $7(27)$ & \\
\hline Occipital & $2(9)$ & $1(4)$ & \\
\hline Parieto-occipital & & $2(8)$ & \\
\hline Temporal-parietal & & $1(4)$ & \\
\hline Temporal insular & & $2(8)$ & \\
\hline Radiotherapy after surgery ${ }^{\mathrm{a}, \mathrm{e}}(n ; \%)$ & $4(17)$ & $10(39)$ & 0.103 \\
\hline Chemotherapy after surgery ${ }^{\mathrm{e}}(n ; \%)$ & $3(13)$ & $7(27)$ & 0.299 \\
\hline Psychotropic medication at $\mathrm{T}^{\mathrm{f}}(n ; \%)$ & $11(48)$ & $17(65)$ & 0.215 \\
\hline Cognitive impairment ${ }^{\mathrm{g}}$ at T3 $(n ; \%)$ & $16(70)$ & $16(69)$ & 0.980 \\
\hline Low PRO scores ${ }^{\mathrm{h}}$ at $\mathrm{T} 3(n ; \%)$ & $14(61)$ & $18(69)$ & 0.539 \\
\hline Involvement of informal caregiver & $16(70)$ & $20(77)$ & 0.339 \\
\hline
\end{tabular}

ASA American Society of Anaesthesiologists, PROs patient reported outcomes

${ }^{a}$ Fisher's Exact Test was interpreted, since not all cell counts were greater than five

${ }^{b}$ Proportions of patients with meningioma and glioma were compared between groups (not separated by tumor grade)

${ }^{c}$ Patients with bilateral tumors were excluded for the statistical comparison

${ }^{\mathrm{d}}$ Proportions of patients with tumors with frontal involvement (vs. non-frontal involvement) were compared between groups

${ }^{\mathrm{e}}$ During study participation (i.e. within one-year post-surgery)

${ }^{\mathrm{f}}$ Use of anti-epileptic drugs, corticosteroid drugs, benzodiazepines, opioids, antipsychotics, stimulants and/ or antidepressants

${ }^{\mathrm{g}} Z$ score $\leq-1.5$ on one or more performance-based outcomes

${ }^{\mathrm{h}} Z$ score $\leq-1.5$ on one or more PROs was observed in 16 participants (70\%). Furthermore, 14 participants completed the retraining more than once.

The evaluation questionnaire was fully completed by $21 / 23$ participants, and partly by one (Table 2 ). $90 \%$ of participants rated to program as "good" or "excellent", and 95\% indicated that they would recommend the program to others. Overall, the level of difficulty and amount of information in the strategy training was perceived as sufficient 
Table 2 Post-intervention ratings of different aspects of ReMind $(n=22)$

\begin{tabular}{|c|c|c|c|}
\hline Difficulty of & (Too) easy & Just right & (Too) difficult \\
\hline Information in strategy training & 7 & 13 & 2 \\
\hline Fill-in exercises in strategy training & 9 & 7 & 4 \\
\hline Retraining (C-Car game) & 13 & 8 & - \\
\hline Amount/number of & (Too) little/few & About right & (Too) much/many \\
\hline Information in strategy training & 1 & 19 & 2 \\
\hline Fill-in exercises in strategy training & - & 7 & 14 \\
\hline Retraining exercises ( $C$-Car game) & 11 & 10 & 1 \\
\hline Supervision by the researcher/trainer & - & 22 & - \\
\hline Usefulness of & (Very) useful & Neutral & Not useful \\
\hline Information in strategy training ${ }^{a}$ & 14 & 5 & 2 \\
\hline Fill-in exercises in strategy training ${ }^{a}$ & 5 & 10 & 5 \\
\hline Retraining exercises ( $C$-Car game) & 19 & 2 & 1 \\
\hline (Telephone) contact with the researcher/trainer & 16 & 6 & - \\
\hline \multirow[t]{2}{*}{ Content addressed daily problems } & Fully/largely & Partly & Not \\
\hline & 10 & 7 & 4 \\
\hline \multirow[t]{2}{*}{ Application of learnt (strategies) in daily life } & Often/regularly & Sometimes & Seldom/never \\
\hline & 9 & 7 & 6 \\
\hline \multirow[t]{2}{*}{ Impact of cognitive problems has changed } & Yes, positively & $\mathrm{No}^{\mathrm{b}}$ & Yes, negatively \\
\hline & 10 & 11 & - \\
\hline \multirow[t]{2}{*}{ Coping with cognitive problems has changed } & Improved coping & $\mathrm{No}^{\mathrm{c}}$ & Worsened coping \\
\hline & 6 & 16 & - \\
\hline \multirow[t]{3}{*}{ Pleasantness of working on ReMind } & (Very) pleasant & Neutral & (Very) unpleasant \\
\hline & 7 & 14 & - \\
\hline & Excellent/good & Sufficient & Insufficient/poor \\
\hline Using an iPad-app for cognitive rehabilitation & 20 & 2 & - \\
\hline Capability of the researcher/trainer & 20 & 2 & - \\
\hline Contact with the researcher/trainer & 21 & 1 & - \\
\hline \multirow[t]{2}{*}{ Overall rating of the program } & 19 & 1 & 1 \\
\hline & Yes & No & \\
\hline Recommendation to other brain tumor patients & 21 & 1 & \\
\hline
\end{tabular}

${ }^{\mathrm{a}}$ Missing values for two participants

${ }^{b}$ No change, there was no impact on daily life (7) or no change, impact remained the same (4)

${ }^{\mathrm{c}}$ Coping is still good (14), or coping is still not good (2) and participants indicated that the information was useful. However, 14 indicated that there were (too) many fill-in exercises included in the strategy training. Furthermore, 11 reported that there were (too) few exercises included in the retraining and 13 that the retraining was (too) easy. Nevertheless, these exercises were perceived as (very) useful by 19 participants. All participants indicated to have appreciated the tablet-based delivery of the program and 16 indicated that the (telephone) contact was (very) useful.

\section{Performance-based cognitive outcomes}

Mean scores of the groups at the different time points are listed in Table 3 and mean changes over time are presented in Fig. 2. Repeated measures ANOVAs demonstrated no significant interaction effects of time and group on the outcome variables (all $p$ values $>0.05$ ). Regarding cognitive performance, significant positive main effects of time (irrespective of group) were observed for processing speed $(F(2,84)=8.658, p<.001)$, complex attention $(F(2,80)=6.253, p=.003)$, cognitive flexibility $(F(2,82)=9.028, p=<0.001)$ and working memory $(F(2,78)=3.147, p=.048)$. Proportions of participants with impairment in cognitive performance were not significantly different between the groups at T3 and T6, with percentages lying around $70 \%$ (Table 3). At T12, significantly fewer participants in the intervention group showed cognitive impairment (35\% vs. $68 \%, p=.027)$.

Over the first interval (T3-T6), $48 \%$ of the participants in the intervention group and $23 \%$ of the participants in the control group showed reliable improvements on one or more cognitive outcomes, and reliable decline was observed in 
Table 3 Mean Z-scores of the intervention group and control group on cognitive performance and PROs per time-point

\begin{tabular}{|c|c|c|c|c|c|c|}
\hline & \multicolumn{3}{|c|}{ Intervention group } & \multicolumn{3}{|c|}{ Control group } \\
\hline & T3 $(\boldsymbol{n}=\mathbf{2 3})$ & T6 $(n=23)$ & $\mathrm{T} 12(\boldsymbol{n}=\mathbf{2 0})$ & $\mathrm{T} 3(\boldsymbol{n}=\mathbf{2 6})$ & T6 $(n=26)$ & $\mathrm{T} 12(\boldsymbol{n}=\mathbf{2 5})$ \\
\hline \multicolumn{7}{|l|}{ Cognitive performance outcomes } \\
\hline Verbal Memory & -0.41 & -0.10 & 0.09 & -0.68 & -0.64 & -0.68 \\
\hline Visual Memory & 0.13 & 0.09 & -0.07 & -0.37 & -0.45 & -0.56 \\
\hline Processing Speed & -0.36 & -0.07 & 0.09 & -0.60 & -0.51 & 0.00 \\
\hline Psychomotor Speed & -0.22 & -0.28 & 0.12 & -0.36 & -0.38 & -0.27 \\
\hline Reaction Time & -0.55 & -0.44 & -0.13 & -1.36 & -1.32 & -1.46 \\
\hline Complex Attention & -1.54 & -0.35 & 0.00 & -1.22 & -0.75 & -0.51 \\
\hline Cognitive Flexibility & -0.98 & -0.45 & -0.18 & -1.19 & -0.77 & -0.57 \\
\hline Working Memory & -0.06 & 0.09 & 0.34 & -0.05 & 0.05 & 0.15 \\
\hline Verbal Fluency & -0.34 & -0.33 & -0.05 & -0.60 & -0.28 & -0.25 \\
\hline $\begin{array}{l}\text { Impaired on } \geq 1 \text { performance-based } \\
\text { outcomes }(n ; \%)\end{array}$ & $16 / 23(70)$ & $15 / 23(65)$ & $7 / 20(35)$ & $19 / 26(73)$ & $18 / 26(69)$ & $17 / 25(68)$ \\
\hline \multicolumn{7}{|l|}{ Patient Reported Outcomes } \\
\hline Cognitive complaints (CFQ) & -0.43 & -0.07 & 0.23 & 0.12 & 0.23 & 0.08 \\
\hline Behavioral regulation (BRIEF-A) & -0.13 & 0.19 & - & 0.10 & 0.26 & - \\
\hline Metacognition (BRIEF-A) & -0.66 & -0.27 & - & -0.41 & -0.24 & - \\
\hline Physical fatigue (MFI) & -0.63 & -0.52 & -0.29 & -0.66 & -0.81 & -0.46 \\
\hline Mental fatigue (MFI) & -0.96 & -0.69 & -0.42 & -1.04 & -0.74 & -0.63 \\
\hline Anxiety symptoms (HADS) & 0.12 & 0.26 & 0.19 & 0.18 & 0.37 & 0.38 \\
\hline Depressive symptoms (HADS) & -0.02 & -0.09 & 0.26 & 0.19 & 0.13 & 0.11 \\
\hline Impaired on $\geq 1$ PRO $(n ; \%)$ & $14 / 23(61)$ & $9 / 23(39)$ & $5 / 20(25)$ & $18 / 26(69)$ & $14 / 26(54)$ & $13 / 25(52)$ \\
\hline
\end{tabular}

Higher mean scores indicate better outcomes

$C F Q$ cognitive failures questionnaire, BRIEF-A behaviour rating inventory of executive function, $M F I$ multidimensional fatigue inventory, $H A D S$ hospital anxiety and depression scale

respectively $30 \%$ vs. $15 \%$. Between $\mathrm{T} 3$ and T12, improvement was observed in $35 \%$ of the participants in the intervention group vs. $24 \%$ of the controls, and decline in respectively $20 \%$ vs. $32 \%$ (all $p$ 's $>0.05$ ).

\section{Patient-reported outcomes}

For the PROs, no significant interaction effects of time and group on the outcome variables (all $p$ values $>0.05$ ) were found. Positive main effects of time were observed, indicating fewer concerns with respect to behavioral regulation $(F(1,46)=8.439, p=.006)$, metacognition $(F(1,46)=9.149$, $p=.004)$ and mental fatigue $(F(2,70)=4.003, p=.022)$. In the comparison of proportions of impaired scores, no significant between-group differences were demonstrated for any of the time-points.

Over the first interval, $83 \%$ of the participants in the intervention group, and $89 \%$ of the controls improved reliably on one or more PROs. Reliable decline was observed in 30 and $19 \%$ of the participants in the intervention group and control group respectively. Over the follow-up interval, improvements were observed for $85 \%$ of the intervention group vs.
$72 \%$ of the controls, and decline was observed in $10 \%$ vs. $20 \%$ respectively (all $p$ 's $>0.05$ ).

\section{Discussion}

In this RCT, the effects of a tablet-based cognitive rehabilitation program starting three months after neurosurgery were evaluated in 49 adults with low-grade glioma and meningioma. Recruitment of patients before surgery was challenging. Adherence rates were however adequate, with participants completing on average $85 \%$ of the strategy training and $91 \%$ of the retraining. $90 \%$ of participants rated the program as "good" or "excellent", and $95 \%$ indicated that they would recommend the program to other brain tumor patients. In general, means over time for cognitive performance test scores (with corrections for practice-effects) and PROs appeared to improve in both groups, and both improvements and declines were observed at the individual level. However, no significant differences were demonstrated between the intervention group $(n=23)$ and controls $(n=26)$ on group means over time and RCIs. 
Our previous RCT, evaluating the face-to-face version of the cognitive rehabilitation program in lower-grade glioma patients with cognitive complaints and disorders, demonstrated positive effects on mental fatigue and performance on memory and attention tests [19]. Several differences in study design may explain findings of the current trial. Compared to our current RCT in 49 brain tumor patients, data from many more patients were evaluated in our previous study $(n=135)$, with much larger statistical power. Initially, we aimed to include 50 patients per group. However, recruitment of participants was difficult, which resulted in underpowered statistical analyses. Unfortunately, recruitment problems are common in psycho-oncological studies, especially in RCTs $[43,44]$. Timing of the intervention in the current study may have played a large role here as well. Many patients (52\%) were not eligible for inclusion, and additionally, a substantial part of patients declined participation. The majority (56\%) mentioned that it would to be too burdensome for them. Of course, the targeted patients face a complex period after surgery. In this period, they need time for recovery and adjuvant treatment, learn to cope with their diagnosis and symptoms, and prefer to devote their time to family, home, work resumption, and social and leisure activities. In our previous RCT, we selected participants based on presence of cognitive complaints and/or deficits and years after treatment [19]. In the current study we chose to adopt an early, preventative and inclusive approach, given that a very large proportion of people with brain tumors experience cognitive deficits at a certain point during the disease trajectory. However, based on our findings, we can conclude that for a substantial group of patients, this early approach does not seem to meet their needs.

Also, not only people with glioma $(n=20)$ were included in the study but also people with meningioma $(n=29)$, who may respond to cognitive rehabilitation in different ways. Unfortunately, the small sample size hampered subgroup analyses on differences in outcomes for meningioma vs. glioma, adherent vs. non-adherent participants and those who involved informal caregivers vs. patients who did not. Furthermore, it is possible that positive preventative effects of the intervention may have been measurable at a later stage (>6 months post-intervention), which would have required a longer follow-up period.

Furthermore, an eHealth instead of face-to-face cognitive rehabilitation program was used in this study. To our knowledge, this is the first study on eHealth cognitive rehabilitation in brain tumor patients. eHealth has the potential to deliver intervention programs to many patients in a costefficient way [45]. Research has demonstrated that psychological eHealth interventions can be as effective as face-toface programs [46], especially when support is offered, using a blended care approach $[47,48]$, as in the current trial. A recent practical guideline of the World Health Organization stated that in case of translation of a non-digital validated intervention to a digital intervention, evaluation can focus on the performance of the digital health intervention's delivery system [49]. In our study, all patients appreciated the tabletbased delivery of the program, all indicated that the amount of supervision (two-weekly phone calls) was 'about right', and their adherence to the program was adequate.

In sum, a large number of variables may explain the differences in findings between the previous and the current trial. These include (a) patient factors (differences in brain disease, the stage and duration thereof, presence of cognitive impairments and cognitive complaints, patient needs and motivation, and timing of medical treatments); (b) intervention factors (e.g., preventative versus rehabilitative aim/ approach, mode of delivery, intensity of therapist contact, involvement of significant others) as well as (c) methodological variables (differences in sample sizes, possible statistical techniques, and types of outcome assessment). These factors, additionally including sociodemographic factors (e.g., age, education), other intervention (e.g., duration, frequencies and number of sessions) and study factors (e.g., control for practice and other non-treatment effects and other nontreatment effects), may also explain why mixed results have been found in general within the larger field of cognitive rehabilitation research in these and other patient populations $[18,39-42]$.

A notable finding in our study was that at $\mathrm{T} 12$, a significant difference in proportions of individuals with cognitive impairment was found between the intervention group (35\%) and controls (68\%), while percentages between groups were comparable at T3 and T6 $( \pm 70 \%)$. This may be partly explained by the observation that pre-intervention scores of the patients in the intervention group seemed already, although not statistically, slightly higher: Post-surgical cognitive improvements over time may have led to a higher percentage of patients in the intervention group reaching normal (non-impaired) ranges at $\mathrm{T} 12$. The fact that the groups were not equal for age and sex may have contributed to this. On the other hand, the differences in proportions on T12 may also suggest small beneficial effects of ReMind, in combination with the observed non-significant differences in change scores over time in favor of the intervention group.

In the meantime, a feasibility study $(n=12)$ by the University of California, San Francisco, demonstrated that the English version of ReMind was well received by adults with lower-grades glioma. Currently, a feasibility clinical trial is ongoing in the same center in which participants with lower grade gliomas are first offered a one-on-one cognitive rehabilitation option $(n=20)$. If they decline due to logistical reasons, they are randomly assigned to ReMind $(n=20)$, or to an automated texting program $(n=20)$. Changes in cognition and HRQOL will be correlated with serial imaging at pre-intervention compared to short and intermediate-term 
follow-up (e.g., in T2 flair hyperintensity volume, diffusion, and resting-state fMRI) [50]. Results of the study are awaited.

To recapitulate, the difficulty recruiting patients for this cognitive rehabilitation intervention suggests that cognitive rehabilitation at this early stage of the disease does not meet the needs of all adults with brain tumors. Patient-tailored timing of ReMind (with respect to medical treatment, presence of cognitive impairments and cognitive complaints, and motivation) could have resulted in a larger sample and more reliable statistics, perhaps with more positive findings as the data cautiously suggest. In clinical practice, neuropsychological interventions can be better tailored to the needs and circumstances of patients and family members, and rehabilitation goals can be set in collaboration. Also, more work on treatment options for cognitive deficits in adults with brain tumors is needed, wherein eHealth can be a promising tool.

Acknowledgements We would like to thank the research assistants for their contributions to the data collection.

Author contributions The study conception and design were primarily set up by KG, MS and GJR. All authors contributed to the multicenter design of the study. SL collected the data, and data analysis was performed by SL and KG. The first draft of the manuscript was written by SL and all authors commented on previous versions of the manuscript. All authors read and approved the final manuscript.

Funding This research was supported by the Dutch organization for health research and innovation (Zonmw) (Grant Number: 842003009).

Data availability Research data will not be shared.

\section{Declarations}

Conflict of interest The authors declare that there is no conflict of interest.

Ethical approval The study was approved by the local medical ethical review board (METC Brabant: NL51152.028.14). All participants provided written informed consent.

Open Access This article is licensed under a Creative Commons Attribution 4.0 International License, which permits use, sharing, adaptation, distribution and reproduction in any medium or format, as long as you give appropriate credit to the original author(s) and the source, provide a link to the Creative Commons licence, and indicate if changes were made. The images or other third party material in this article are included in the article's Creative Commons licence, unless indicated otherwise in a credit line to the material. If material is not included in the article's Creative Commons licence and your intended use is not permitted by statutory regulation or exceeds the permitted use, you will need to obtain permission directly from the copyright holder. To view a copy of this licence, visit http://creativecommons.org/licenses/by/4.0/.

\section{References}

1. Meskal I, Gehring K, Rutten GM, Sitskoorn MM (2016) Cognitive functioning in meningioma patients: a systematic review. J Neurooncol 128(2):195-205. doi:https://doi.org/10.1007/ s11060-016-2115-z

2. Van Loon EM, Heijenbrok-Kal MH, van Loon WS et al (2015) Assessment methods and prevalence of cognitive dysfunction in patients with low-grade glioma: a systematic review. J Rehabil Med 47(6):481-488. doi:https://doi.org/10.2340/16501977-1975

3. IJzerman-Korevaar M, Snijders TJ, de Graeff A et al (2018) Prevalence of symptoms in glioma patients throughout the disease trajectory: a systematic review. J Neurooncol 40:485-496. doi:https://doi.org/10.1007/s11060-018-03015-9

4. Satoer D, Visch-Brink E, Smits M, Kloet A, Looman C, Dirven C, Vincent A (2014) Long-term evaluation of cognition after glioma surgery in eloquent areas. J Neurooncol 116(1):153-160. doi:https://doi.org/10.1007/ss11060-013-1275-3

5. Talacchi A, Santini B, Savazzi S, Gerosa M (2011) Cognitive effects of tumour and surgical treatment in glioma patients. J Neurooncol 103(3):541-549. doi:https://doi.org/10.1007/ s11060-010-0417-0

6. Rijnen SJM, Meskal I, Bakker M, De Baene W, Rutten GM, Gehring K, Sitskoorn MM (2019) Cognitive outcomes in meningioma patients undergoing surgery: individual changes over time and predictors of late cognitive functioning. Neuro Oncol 121(7):911-922. doi:https://doi.org/10.1093/neuonc/noz039

7. Boele FW, Meads D, Jansen F et al (2020) Healthcare utilization and productivity loss in glioma patients and family caregivers: the impact of treatable psychological symptoms. J Neurooncol 147(2):485-494. doi:https://doi.org/10.1007/ s11060-020-03454-3

8. Nugent BD, Weimer J, Choi CJ, Bradley CJ, Bender CM, Ryan $\mathrm{CM}$ et al (2014) Work productivity and neuropsychological function in persons with skull base tumors. Neurooncol Pract 1:106113. doi:https://doi.org/10.1093/nop/npu015

9. Feuerstein M, Hansen JA, Calvio LC, Johnson L, Ronquillo JG (2007) Work productivity in brain tumor survivors. J Occup Environ Med 49:803-811. doi:https://doi.org/10.1097/JOM.0b013 e318095a458

10. Day J, Gillespie DC, Rooney AG et al (2016) Neurocognitive deficits and neurocognitive rehabilitation in adult brain tumors. Curr Treat Options Neurol 18(5):22. doi:https://doi.org/10.1007/ s11940-0160406-5

11. Van Coevorden-Van Loon EMP, Coomans MB, Heijenbrok-Kal MH, Ribbers GM, Van den Bent MJ (2017) Fatigue in patients with low grade glioma: systematic evaluation of assessment and prevalence. J Neurooncol 133(2):237-246. doi:https://doi.org/10. 1007/s11060-017-2454-4

12. Van der Linden SD, Gehring K, Rutten GM, Kop WJ, Sitskoorn MM (2020) Prevalence and correlates of fatigue in patients with meningioma before and after surgery. Neurooncol Pract 7(1):7785. doi:https://doi.org/10.1093/nop/npz023

13. Rofes A, Mandonnet E, de Aguiar V, Rapp B, Tsapkini K, Miceli $G$ (2019) Language processing from the perspective of electrical stimulation mapping. Cognit Neuropsychol 36(3-4):117-139. https://doi.org/10.1080/02643294.2018.1485636

14. Imberger J, Ruge M, Kreth FW et al (2008) Intraoperative mapping of language functions: a longitudinal neurolinguistic analysis. J Neurosurg 109(4):583-592. doi:https://doi.org/10.3171/JNS/ 2008/109/10/0583

15. Van de Bent MJ, Smits M, Kros JM, Chang SM (2017) Diffuse Infiltrating Oligodendroglioma and Astrocytoma. J Clin Oncol 35(21):2394-2401. doi:https://doi.org/10.1200/JCO.2017.72.6737 
16. Linsler S, Keller C, Urbschat S, Ketter R, Oertel J (2016) Prognosis of meningiomas in the early 1970s and today. Clin Neurol Neurosurg 149:98-103. doi:https://doi.org/10.1016/j.clineuro. 2016.08.007

17. Amidei C (2018) Symptom-based interventions to promote quality survivorship. Neurooncol Pract 20(s7):27-39. doi:https://doi.org/ 10.1093/enuonc/noy 100

18. Van Lonkhuizen PJC, Klaver KM, Wefel JS et al (2019) Interventions for cognitive problems in adults with brain cancer: A narrative review. Eur J Cancer Care 28(3):e13088. doi:https://doi.org/ 10.1111/ecc. 13088

19. Gehring K, Sitskoorn MM, Gundy CM et al (2009) Cognitive rehabilitation in patients with gliomas: a randomized, controlled trial. J Clin Oncol 27(22):3712-3722. doi:10.1200/ JCO.2008.20.5765

20. Gehring K, Aaronson NK, Gundy CM, Taphoorn MJB, Sitskoorn MM (2011) Predictors of neuropsychological improvement following cognitive rehabilitation in patients with gliomas. J Int Neuropsychol Soc 17(2):256-266. doi:https://doi.org/10.1017/S1355 617710001530

21. Zucchella C, Capone A, Codella V et al (2013) Cognitive rehabilitation for early post-surgery inpatients affected by primary brain tumor: a randomized, controlled trial. J Neurooncol 114(1):93100. doi:https://doi.org/10.1007/s11060-013-1153-z

22. Maschio M, Dinapoli L, Fabi A, Giannarelli D, Cantelmi T (2015) Cognitive rehabilitation training in patients with brain tumorrelated epilepsy and cognitive deficits: a pilot study. J Neurooncol 125(2):419-426. https://doi.org/10.1007/s11060-015-1933-8

23. Richard NM, Bernstein LJ, Mason WP et al (2019) Cognitive rehabilitation for executive dysfunction in brain tumor patients: a pilot randomized controlled trial. J Neurooncol 142(3):565-575. doi:https://doi.org/10.1007/s11060-019-03130-1

24. Gehring K, Aaronson NK, Taphoorn MJB, Sitskoorn MM (2011) A description of a cognitive rehabilitation programme evaluated in brain tumour patients with mild to moderate cognitive deficits. Clin Rehabil 25(8):675-692. doi:https://doi.org/10.1177/02692 15510395791

25. Van der Linden SD, Sitskoorn MM, Rutten GJM, Gehring K (2018) Feasibility of the evidence-based cognitive telerehabilitation program ReMind for patients with primary brain tumors. J Neurooncol 137(3):523-532. doi:https://doi.org/10.1007/ s11060-017-2738-8

26. Van der Linden SD, Sitskoorn MM, Rutten GJM, Gehring K (2019) Study Protocol for a Randomized Controlled Trial Evaluating the Efficacy of an Evidence-Based App for Cognitive Rehabilitation in Patients with Primary Brain Tumours. Neurosurg 85(2):273-279. doi:https://doi.org/10.1093/neuros/nyy254

27. World Medical Association (2013) World Medical Association Declaration of Helsinki: Ethical Principles for Medical Research Involving Human Subjects. JAMA 310(20):2191-2194. doi:https://doi.org/10.1001/jama.2013.281053

28. Scott NW, McPherson GC, Ramsay CR, Campbell MK (2002) The method of minimization for allocation to clinical trials. a review. Control Clin Trials 23(6):662-674. doi:https://doi.org/10. 1016/s0197-2456(02)-242-8

29. ALEA Online Randomisation Software. Available at: http://www. aleaclinical.eu. Accessed 28 Mar 2018

30. Gualtieri CT, Johnson LG (2006) Reliability and validity of a computerized neurocognitive test battery, CNS Vital Signs. Arch Clin Neuropsychol 21(7):623-643. doi:https://doi.org/10.1016/j. acn.2006.05.007

31. Schmand B, Groenink SC, Van den Dungen M (2008) Letter fluency: psychometrische eigenschappen en Nederlandse normen. GEEG 39(2):64-74
32. Wechsler D (2015) Wechsler Adult Intelligence Scale. Nederlandstalige bewerking, 3rd edn. Technische handleiding. Harcourt Test Publishers, Amsterdam

33. Rijnen SJM, Meskal I, Emons WHM et al (2017) Evaluation of normative data of a widely used computerized neuropsychological battery: applicability and effects of sociodemographic variables in a Dutch sample. Assessment. https://doi.org/10.1177/1073191117 727346

34. Ponds R, van Boxtel MPJ, Jolles J (2006) De Cognitive Failure Questionnaire als maat voor subjectief cognitief functioneren [The Cognitive Failures Questionnaire as a measure for subjective cognitive functioning]. Tijdschrift Voor Neuropsychologie 1(2):37-45

35. Scholte E, Noens I (2011) BRIEF-A. Vragenlijst over executief functioneren bij volwassenen. Handleiding. Hogrefe, Amsterdam

36. Schwarz R, Krauss O, Hinz A (2003) Fatigue in the general population. Onkologie 26(2):140-144

37. Spinhoven P, Ormel J, Sloekers PP, Kempen GI, Speckens AE, Van Hemert AM (1997) A validation study of the Hospital Anxiety and Depression Scale (HADS) in different groups of Dutch subjects. Psychol Med 27(2):363-370. doi:https://doi.org/10. $1017 / \mathrm{ss} 0033291796004382$

38. Maassen GH, Bossema E, Brand N (2009) Reliable change and practice effects: Outcomes of various indices compared. J Clin Exp Neuropsychol 31(3):339-352. doi:https://doi.org/10.1080/ 13803390802169059

39. Loetscher T, Potter KJ, Wong D, das Nair R, (2019) Cognitive rehabilitation for attention deficits following stroke. Cochrane Database Syst Rev. https://doi.org/10.1002/14651858.CD002842. pub3

40. Cicerone KD, Goldin Y, Ganci K, Rosenbaum A, Wethe JV, Langenbahn DM, Malec JF, Bergquist TF, Kingsley K, Nagele D, Trexler L, Fraas M, Bogdanova Y, Harley JP (2019) EvidenceBased Cognitive Rehabilitation: Systematic Review of the Literature From 2009 Through 2014. Arch Phys Med Rehabil 100(8):1515-1533. doi:https://doi.org/10.1016/j.apmr.2019.02. 011. Epub 2019 Mar 26

41. Kumar KS, Samuelkamaleshkumar S, Viswanathan A, Macaden AS (2017) Cognitive rehabilitation for adults with traumatic brain injury to improve occupational outcomes. Cochrane Database Syst Rev CD007935. doi:https://doi.org/10.1002/14651858

42. Rosti-Otajärvi EM, Hämäläinen PI (2014) Neuropsychological rehabilitation for multiple sclerosis. Cochrane Database Syst Rev 11(2):CD009131. doi:https://doi.org/10.1002/14651858.CD009 131.pub3

43. Grunfeld E, Zitzelsberger L, Coristine M, Aspelund F (2002) Barriers and facilitators to enrollment in cancer clinical trials: qualitative study of the perspectives of clinical research associates. Cancer 1(7):1577-1583. doi:https://doi.org/10.1186/1471-2288-9-14

44. Wakefield CE, Fardell JE, Doolan EL et al (2017) Paricipation in psychosocial oncology and quality-of-life research: a systematic review. Lancet Oncol 18(3):e153-e165. doi:https://doi.org/10. 1016/S1470-2045(17)30100-6

45. Elbert NJ, van Os-Medendorp H, van Renselaar W, Ekeland AG, Hakkaart-van Roijen L, Raat H, Nijsten TE, Pasmans SG (2014) Effectiveness and cost-effectiveness of ehealth interventions in somatic diseases: a systematic review of systematic reviews and meta-analyses. J Med Internet Res 16(4):e110. doi:https://doi.org/ 10.2196/jmir.2790

46. Barak A, Hen L, Boniel-Nissim M, Shapira N (2008) A comprehensive review and a meta-analysis of the effectiveness of internet-based psychotherapeutic interventions. J Technol Hum Serv 26(2-4):109-160. https://doi.org/10.1080/152288308020944 29

47. Andersson G, Titov N (2014) Advantages and limitations of Internet-based interventions for common mental disorders. World Psychiatry 13(1):4-11. doi:https://doi.org/10.1002/wps.20083 
48. Richard D, Richardson T (2012) Computer-based psychological treatments for depression: a systematic review and meta-analysis. Clin Psychol Rev 32(4):329-342. doi:https://doi.org/10.1016/j. cpr.2012.02.004

49. World Health Organization (2016) Monitoring and evaluating digital health interventions: a practical guide to conducting research and assessment. World Health Organization, Geneva

50. Rehabilitation and Longitudinal Follow-up of Cognition in Adult Lower Grade Gliomas https://clinicaltrials.gov/ct2/show/NCT03
948490 ?term $=$ cognitive $\&$ cond $=$ Glioma $\&$ cntry $=$ US \& state $=$ US $\% 3$ ACA \& city $=$ San + Francisco $\& d r a w=2 \&$ rank $=1$. Accessed 28 July 2021

Publisher's Note Springer Nature remains neutral with regard to jurisdictional claims in published maps and institutional affiliations. 